\title{
The use of Robinia pseudoacacia L fruit extract as a green corrosion inhibitor in the protection of copper-based objects
}

\author{
Vahid Pourzarghan ${ }^{1}$ and Bahman Fazeli-Nasab ${ }^{2^{*}}$ (D)
}

\begin{abstract}
The most important inhibitors used in bronze disease are BTA and AMT. While these inhibitors control corrosion, they are toxic and cancerous. In this study, the acacia fruit extract (200 ppm to $1800 \mathrm{ppm}$ ) was used to the prevention of corrosion inhibition of bronze alloy in corrosive sodium chloride solution $0.5 \mathrm{M}$, for 4 weeks consecutively. The Bronze alloy used in this research, was made based on the same percentage as the ancient alloys (CU-10Sn). IE\% was used to obtain the inhibitory efficiency percentage and Rp can be calculated from the resistance of polarization. SEM-EDX was used to evaluate the surfaces of alloy as well as inhibitory. The experiment was conducted in split plot design in time based on the RCD in four replications. ANOVA was performed and comparison of means square using Duncan's multiple range test at one percent probability level. The highest rate of corrosion inhibition (93.5\%) was obtained at a concentration of $1800 \mathrm{ppm}$ with an increase in the concentration of the extract, corrosion inhibition also increased, i.e., more bronze was prevented from burning. Also, the highest corrosion inhibitory activity of Acacia extract (79.66) was in the second week and with increasing duration, this effect has decreased. EDX analysis of the control sample matrix showed that the amount of chlorine was $8.47 \% \mathrm{wt}$, while in the presence of corrosive sodium chloride solution, after 4 weeks, the amount of chlorine detected was 3.20\%wt. According to the morphology (needle and rhombus) of these corrosion products based on the SEM images, it can be said, they are the type of atacamite and paratacamite. They have caused bronze disease in historical bronze works. The green inhibitor of Acacia fruit aqueous extract can play an effective role in inhibiting corrosion of bronze, but at higher concentrations, it became fungal, which can reduce the role of Acacia fruit aqueous extract and even ineffective. To get better performance of green inhibitors, more tests need to be done to improve and optimize.
\end{abstract}

Keywords: Corrosion, Bronze disease, Green inhibitors, Acacia, Potentiostat, SEM-EDX

\section{Introduction}

There are some growing concerns about the use of green inhibitors because some of these inhibitors are not only toxic to living organisms but also cause environmental damage although some be helpful and nontoxic, they are less effective. When choosing an inhibitor, it is important to consider the cost of the inhibitor, access

\footnotetext{
*Correspondence: Bfazeli@uoz.ac.ir

${ }^{2}$ Research Department of Agronomy and Plant Breeding, Agricultural Research Institute, University of Zabol, Zabol, Iran

Full list of author information is available at the end of the article
}

to the inhibitor (materials would be expensive if access is limited), and its environmental friendliness. Inhibitors are volatile, inactive (anodic), precipitated, cathodic, organic and inorganic compounds that prevent corrosion through adsorbing ions or molecules from the metal surface, increasing or decreasing anodic or cathodic reaction, reducing penetration rate of reactants on the metal surface and the electrical resistance of metal surface [1-3].

Inhibitors are generally substances, which reduce the level of chemical reactions at appropriate concentrations. Corrosion inhibitors are active chemical species, which
Springer Open

(c) The Author(s) 2021. This article is licensed under a Creative Commons Attribution 4.0 International License, which permits use, sharing, adaptation, distribution and reproduction in any medium or format, as long as you give appropriate credit to the original author(s) and the source, provide a link to the Creative Commons licence, and indicate if changes were made. The images or other third party material in this article are included in the article's Creative Commons licence, unless indicated otherwise in a credit line to the material. If material is not included in the article's Creative Commons licence and your intended use is not permitted by statutory regulation or exceeds the permitted use, you will need to obtain permission directly from the copyright holder. To view a copy of this licence, visit http://creativeco mmons.org/licenses/by/4.0/. The Creative Commons Public Domain Dedication waiver (http://creativecommons.org/publicdomain/ zero/1.0/) applies to the data made available in this article, unless otherwise stated in a credit line to the data. 
help slow down, delay or prevent corrosion, via different mechanisms, such as adsorption onto the metal surface that blocks active surface sites $[4,5]$. These substances can inhibit the growth of biological agents and stop the physiological processes. The inhibitor at low concentrations in corrosive medium delays the corrosion of metals $[6,7]$. These substances can be solid, liquid, or gas and used in closed, gaseous, and aqueous mediums $[8,9]$.

Corrosion inhibitors reduce the rate of corrosion in several ways: (i) reduce the adsorption of ions/molecules on the metal surface; (ii) increase or decrease the anodic and/or cathodic reaction; to the metal surface, (iv) reduce the electrical resistance of the metal surface [10].

The effective techniques possible for protection are modification of metal, design, corrosive environment, metal environment potential, surface, and the use of inhibitors. Inhibitors are categorized into methods such as mechanism (anodic, cathodic and mixed inhibitors), environment (acid, alkali and neutral inhibitors) and mode of protection (chemical, adsorption, film forming and vapor phase inhibitors) [11].

The inhibitory effect of BTA (Benzotriazole) and AMT (5-amino-2-mercapto-1, 3, 4-thiadiazole) on historical bronze art works has been proved previously [12-15]. While these inhibitors have high efficiency, they have toxic and cancerous impacts on the environment. For this reason, green inhibitors such as honey, fig juice [16], the extract of salvia [17] and green tea extract [18] have been examined and evaluated in recent years.

Most organic corrosion inhibitors have heteroatoms. P, $\mathrm{O}, \mathrm{N}$, and $\mathrm{S}$ are known as active centers $(\mathrm{O}<\mathrm{N}<\mathrm{S}<\mathrm{P})$ for the adsorption process on the metal surface and have a higher electron density. These elements act as corrosion inhibitors. The use of organic compounds containing oxygen, sulfur and especially nitrogen to reduce corrosion attack on steel has been studied in detail. Most organic inhibitors are adsorbed by displacing water molecules on the metal surface and forming a compact barrier. Additionally, the availability of non-bonded electrons (single pair) and $\mathrm{p}$ in inhibitor molecules facilitates the transfer of electrons from the inhibitor to the metal [10].

Rosemary leaves were investigated as corrosion inhibitors for the $\mathrm{Al}+2.5 \mathrm{Mg}$ alloy in a $3 \% \mathrm{NaCl}$ solution at $25^{\circ} \mathrm{C}$ [19], and El-Etre studied natural honey as a corrosion inhibitor for copper [20] and studied opuntia extract on aluminum [21]. The inhibitive influence of the extract of khillah (Ammi visnaga) seeds on the corrosion of SX 316 steel in $\mathrm{HCl}$ solution was determined utilizing weight loss amounts as well as the potentiostatic method. Delonix regia extracts inhibited the corrosion of aluminum in hydrochloric acid extracts [22]. Antibacterial drugs were used as corrosion inhibitors for bronze surfaces in acidic solutions [23]. The results indicate that Myrrh extract has potential to be a corrosion inhibitor for $\mathrm{Cu}$ in acidic environment [24].

The Acacia plant, scientifically named Robinia pseudoacacia L from the Papilionaceae family, is one of the twocelled plants whose beautiful and ornamental flowers cultivated by beekeepers to produce fragrant honey. The flowers have a soothing, stomach tonic effect and astringent and biliary properties [25]. The Acacia plant (robina psudoacacia) is a fast-growing tree. It has a broad crown with leaves consisting of 11-23 dark green oval leaflets. In the roots, bark, and seeds of the Robinia pseudoacacia $\mathrm{L}$ tree, there is a substance called Description Robin, and in the leaves and flowers, there is also a glucoside called Description Robinin. Robinia pseudoacacia L wood is hard and durable. For these reasons, it is of industrial and commercial importance and is used to build columns and scaffolding for mines, as well as to make sofas and chairs [25].

The corrosion inhibitory abilities of tannins, alkaloids, amino acids and organic dyes of plant origin are considered. Although significant research has been devoted to the inhibition of corrosion by plant extracts, reports on the exact mechanisms of the adsorption and identification process of the active substance are still scarce [10]. Therefore, in this study, following various other studies [26], chloride medium has been used to study the corrosion process and based on previous research, it was indicated that the general compounds of the Robinia pseudoacacia L fruit extract contain the natural sugars of ramenoz, arabinose, and galactose, as well as gluconic acid, 4 methoxygluconic and rubinin [27-29] and the application of anti-corrosion effect of Robinia pseudoacacia L fruit extract on mild steel [30-32], the aim of this experiment, Robinia pseudoacacia L fruit extract was used to evaluate the inhibitory effect on bronze alloy (Cu-10Sn).

\section{Material and methods}

Preparation of plant and extract

Robinia pseudoacacia L fruit was obtained from the Agricultural and Natural Resources Research and Training Center of Isfahan (Fig. 1).

Fruit samples collected were dried on a clean cloth and ground under appropriate conditions. $30 \mathrm{~g}$ of the resulting powder was soaked in $100 \mathrm{ml}$ of double distilled water and shaken in a shaker for $24 \mathrm{~h}$ at room temperature. The obtained liquids were passed through sterile filter paper (Watman paper No. 1) and finally the extract and powder were separated. The remaining particles in the extract were separated using a refrigerated centrifuge $(2500 \mathrm{rpm})$ at $4{ }^{\circ} \mathrm{C}$ for $20 \mathrm{~min}$. The extract was dewatered using a vacuum rotary device. The obtained extract was turned into powder and stored in a dark glass at a 

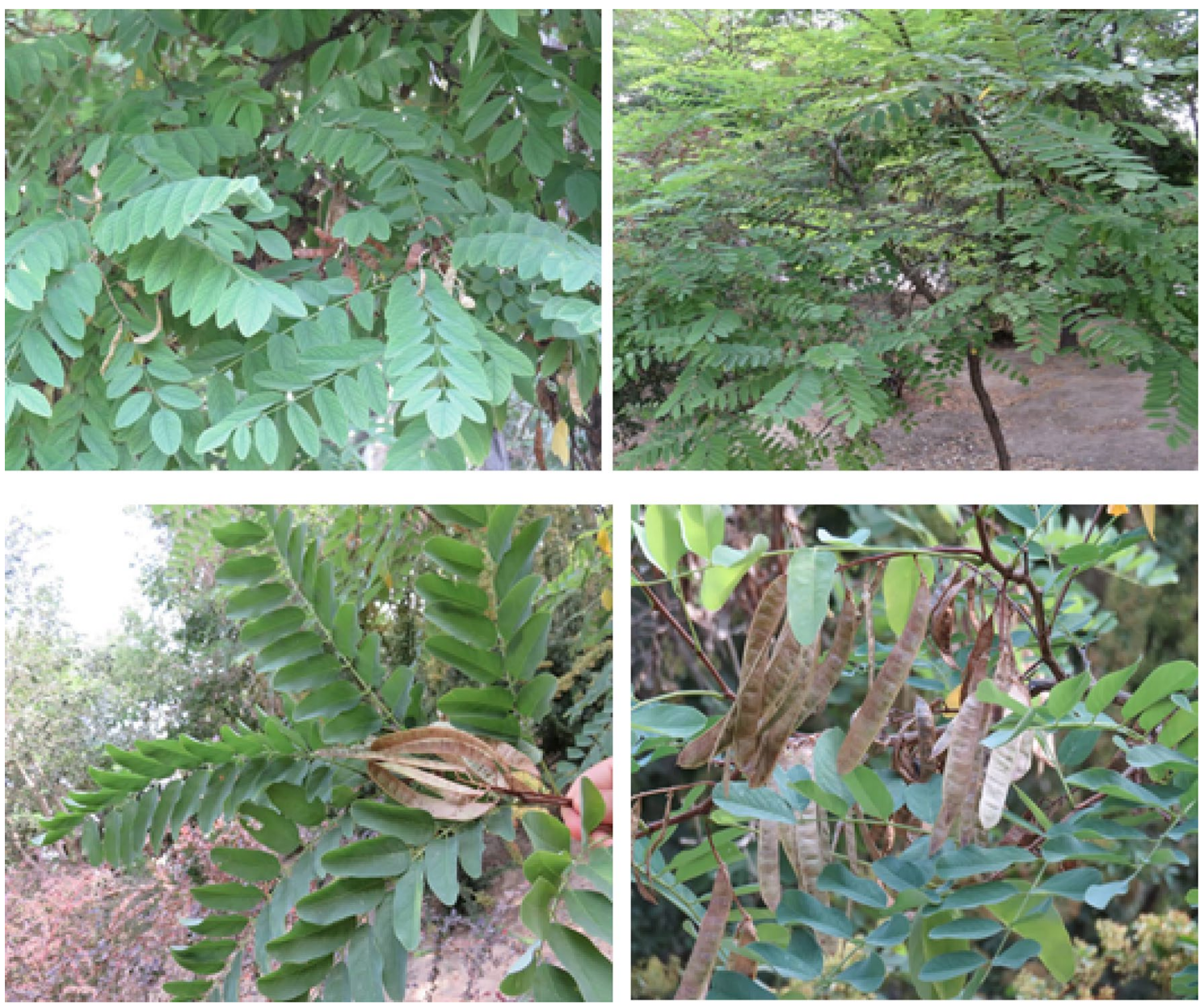

Fig. 1 The characteristic of Robinia pseudoacacia L. plant

temperature of $4{ }^{\circ} \mathrm{C}$. During the experiment, dilutions of 200 to $1800 \mathrm{ppm}$ (Part per Million) were prepared from the extract [33].

\section{Experimental design}

The Acacia fruit extract $(200,400,600,800,1000,1200$, 1400,1600 , and $1800 \mathrm{ppm}$ ) was used to the prevention of corrosion inhibition of bronze alloy in corrosive sodium chloride solution $0.5 \mathrm{M}$, for 4 weeks consecutively. The experiment was conducted in split plot design in time based on a randomized complete design in four replications. Different concentrations of plant extracts were included in the main plots and the duration of application of the plant extract was in the sub-plots [34].

The Bronze alloy used in this research, was made based on the same percentage as the ancient alloys $(\mathrm{Cu}-10 \mathrm{Sn})$ (The alloy used in the research, according to the ancient alloys, with $10 \%$ tin and $90 \%$ copper, was made by casting and finally analyzed to make electrodes and coupons).
This alloy was used for the effect of corrosion inhibitors in the potentiostat device, the weight loss method.

After preparing the coupons with a percentage of $(\mathrm{Cu}-$ $10 \mathrm{Sn}$ ), the coupons were completely polished using sandpaper with grades 400 to 2200 to create a completely smooth surface. Then, the coupons were rinsed with distilled water and degreased by alcohol. The samples were placed in an oven at $120{ }^{\circ} \mathrm{C}$ for $1 \mathrm{~h}$. The coupons were immersed in Robinia pseudoacacia L with concentrations of $1000 \mathrm{ppm}$ for 24 and $48 \mathrm{~h}$. After removing the coupons, they were dried at room temperature for $1 \mathrm{~h}$ and photographed to examine the change in appearance color on the coupon surfaces.

Sodium chloride $(0.5 \mathrm{M})$ was used to make a control solution. This solution was poured into a special container at volume of $100 \mathrm{ml}$. After calibrating, the device begins plotting the polarization curve. In the polarization curve, the corrosion potential of the control solution (Sodium chloride M 0.5) was recorded $-243 \mathrm{mV}$ (Millivolts). 
The Acacia fruit extract was separately mixed and treated with a corrosive solution of sodium chloride $0.5 \mathrm{M}$ with $\mathrm{pH}=5.5$, so that its corrosion power could be examined by the potentiostat device (Table 1) [35]. The corrosion potential of the control solution was obtained $-243 \mathrm{mV}$. Based on the corrosion potential of the sample at the presence of

Table 1 Analysis of variance of the effect of the aqueous extract of Acacia fruit and duration of treatment on the corrosion inhibition of bronze

\begin{tabular}{llrrr}
\hline Source & df & \multicolumn{1}{l}{ SS } & \multicolumn{1}{c}{ MS } & F \\
\hline Concentration of extract & 8 & $33,320.9$ & 4165.11 & $134.50^{* *}$ \\
$r$ & 3 & 197.9 & 65.96 & \\
Error r* Concentration of extract & 24 & 743.2 & 30.97 & \\
Week (period of time) & 3 & $11,575.7$ & 3858.58 & $157.28^{* *}$ \\
Concentration of extract *week & 24 & $16,934.4$ & 705.60 & $28.76^{* *}$ \\
Error r* Concentration of extract & 81 & 1987.2 & 24.53 & \\
$\quad{ }^{*}$ week & & & & \\
Total & 143 & $64,759.3$ & & \\
CV(r concentration) & 8.12 & & & \\
CV(r* concentration *week) & 7.23 & & & \\
\hline
\end{tabular}

** Significant at one percent level

df: Degrees of freedom; SS: sum of Squares; MS: mean sum of squares; F ratio: each $\mathrm{F}$ ratio is computed by dividing the MS value by another MS value. The MS value for the denominator depends on the experimental design the inhibitor solution, $-222 \mathrm{mV}$ indicates a shift toward $21 \mathrm{mV}$ to positive values, which indicates that the type of inhibitor is combinatorial (mixed-type inhibitor (Some anodic and some cathodic)) (Fig. 2). In addition to the change in the potential of corrosion, a slight flow (Slight current drop) is seen in the anodic branch.

If the potential increases continuously, the curve will be anodic polarization and if the potential decreases continuously, the curve will be cathodic polarization. If polarization causes a slight change to the positive or negative, the curve will be of the combined (mixed-type inhibitor) polarization type [35, 36]. It is related that Potentiodynamic if any compounds suppress has both the anodic and cathodic process, it behaves as mixed-type inhibitors [37].

\section{Calculating the corrosion efficiency using potentiostat device calculations}

$I E \%$ was used to obtain the inhibitory efficiency percentage (Formula 1). In this formula, Icorr is density of the corrosion flow with inhibitory and $I^{0}$ is corrosion flow without inhibition.

$$
I E=\frac{I^{0} \text { corr }- \text { Icorr }}{I^{0} \text { corr }} \times 100
$$

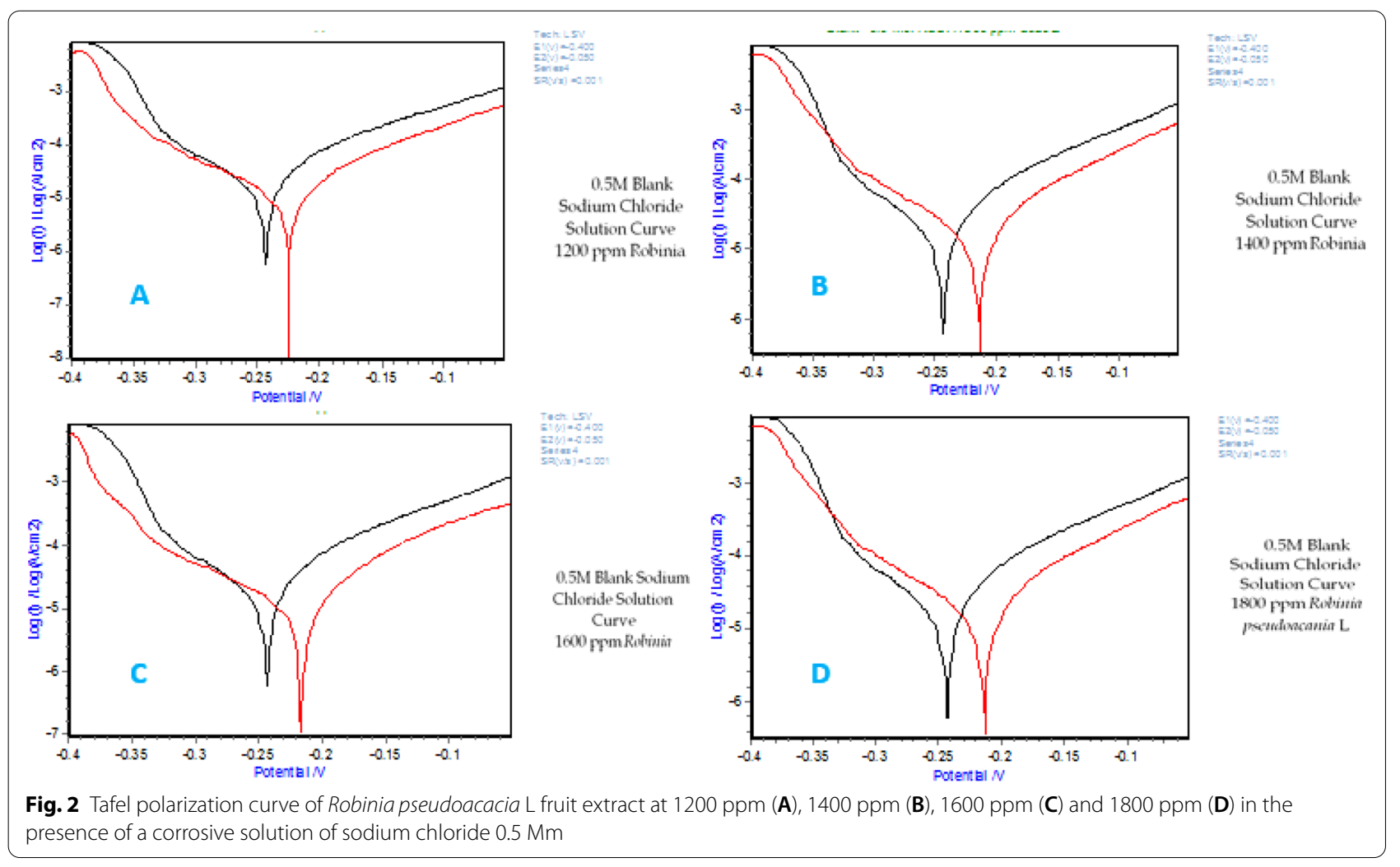


The corrosion current density (The corrosion current density is determined at a constant $\mathrm{pH}$ value of solution using no buffering additives and it was calculated for the obvious specimen surface area) [38] can be calculated from the polarization resistance and the SternGeary constant and also Rp can be calculated from the resistance of polarization (Eq. 2) [39].

$$
\begin{aligned}
& R p=\frac{B}{i_{\text {corr }}} \\
& B=\frac{b_{a} * b_{c}}{2.303\left(b_{a}+b_{c}\right)}
\end{aligned}
$$

$b a=$ slope of the anodic Tafel reaction, when plotted on base 10 logarithmic paper in V/decade, $b c=$ slope of the cathodic Tafel reaction when plotted on base 10 logarithmic paper in V/decade, and $B=$ Stern-Geary constant, $\mathrm{V}$.

In these experiments, corrosion flow density (Formula 3), corrosion rate, and equivalent weight with the presence and absence of inhibitor were calculated by standard (ASTM (American Society for Testing and Materials), G 102-98) [40, 41].

$$
\text { icorr }=\frac{\text { Icorr }}{A}
$$

$i_{\text {corr: }}$ corrosion flow density $\left(\mu \mathrm{A} / \mathrm{cm}^{2}\right) ; I_{\text {corr }}$ : corrosion flow $(\mu \mathrm{A}) ; A=$ contact surface $\left(\mathrm{cm}^{2}\right)$.

Corrosion rate is calculated based on the following equation

$$
C R=K 1 \frac{i \text { corr }}{\rho} E W
$$

$C R=$ corrosion rate $(\mathrm{mpy}) ; K 1=3.27 \times 10^{-3}(\mathrm{~mm} \mathrm{~g} /$ $\mu \mathrm{A} \mathrm{cm}$ yr $) ; \rho=\operatorname{density}\left(\mathrm{g} / \mathrm{cm}^{3}\right)$.

\section{Calculating the classic weight loss}

The weight loss method is the simplest method for studying corrosion inhibitors due to the lack of need for device (except for using the digital scale). In this method, the weight variations of the metal sample are calculated before and after exposure to the corrosive medium (in the absence and presence of inhibitor). The time taken for this experiment is long, but as results of this method are more real than those of the electrochemical method, it is still used [42, 43]. The classic weight loss can be calculated based on the IE formula (Formula 5). In this formula, Wcorr is the weight loss of the sample in the presence of the inhibitor and W0 is the weight loss of the sample in the absence of the inhibitor.

$$
I E=1-\frac{\Delta W \text { inhibitor }}{\Delta W \text { blank }} \times 100
$$

In order to perform the experiment using the classic method, the prepared electrodes were cut with a percentage of $(\mathrm{Cu}-10 \mathrm{Sn})$ as round coupons with a diameter of $0.73 \mathrm{~cm}$ and a thickness of $2 \mathrm{~mm}$.

The coupons were polished using sandpaper with grades of 400, 800, and 2200. The coupons were degreased in alcohol and rinsed in distilled water. The rinsed samples were heated at $80^{\circ} \mathrm{C}$ for $1 \mathrm{~h}$ in an oven.

Then, coupons were placed in a desiccator for $1 \mathrm{~h}$. Finally, the coupons were weighed to be immersed in Robinia pseudoacacia L fruit extract. The inhibitory efficiency of the coupons were calculated each week for 4 week consecutively (Formula 5). Hence, one of the coupons were removed from the control solution and Robinia pseudoacacia L fruit extract each week, after one month of immersion (From the first week to the end).

\section{Determine the inhibitory efficiency of the Robinia pseudoacacia L fruit}

In this paper, the potentiostat device, (SAMA 500 electro-analyzer system model (SAMA Research Center, Iran), was used to perform experiments to determine the inhibitory efficiency of the Robinia pseudoacacia L fruit. It included three electrodes, a platinum auxiliary electrode, a reference electrode of saturated chloride mercury (calomel) and a bar working electrode $[44,45]$ with length of $7.5 \mathrm{~cm}$ and diameter of $0.73 \mathrm{~cm}$ with compound of $\mathrm{Cu}-10 \mathrm{Sn}$ ). It was polished with sandpaper (grade from 400 to 2200). Each of these experiments was repeated four times. To calibrate the device, the LSV (Liner sweep voltammetry) Tafel-plot technique was used. Additionally, the classical weight loss method, and finally, SEM-EDX (Scanning Electron Microscope-Energy Dispersive X-rays), manufactured by Philips Company of the Netherlands. The XL30 model was used to evaluate the surfaces of alloy as well as inhibitory efficiency of the Robinia pseudoacacia L fruit [46, 47].

\section{Scanning Electron Microscope (SEM)}

To accelerate corrosion, the samples were transferred to the humidity compartment. Coupons were placed in a relative humidity of $95 \pm 2$ and a temperature of 25 to $30{ }^{\circ} \mathrm{C}$. The samples underwent sodium chloride $0.5 \mathrm{mM}$ spray based on the standards of ASTMG85 and ISO9227. Four weeks later, the samples were removed from the humidifier compartment and examined to evaluate the effect of the inhibitor on the coupon surfaces by using SEM-EDX device.

To determine the size and morphology of the nanoparticles produced using electron microscopy, the reaction 
mixture was centrifuged three times for $15 \mathrm{~min}$ at a speed of 12,000 rpm. Then, a few drops of the resulting precipitate were dried on a piece of aluminum foil at room temperature and after drying, the SEM photo was taken using an electron microscope device (Philips SEM machine (model CMC-300 kV, Netherlands)).

\section{Statistical analysis of data}

After data collection, analysis of variance was performed using student statistic 9 software as well as comparison of means square using Duncan's multiple range test at one percent probability level.

\section{Results}

Polarization evaluation of Tafel acacia extracts

The Tafel polarization of Robinia pseudoacacia L fruit extract in $1200 \mathrm{ppm}$ at the presence of sodium chloride $0.5 \mathrm{M}$, was shown that the inhibitory corrosion potential is $-216 \mathrm{mV}$. Based on the control solution, inhibitor chart has a shift of direction to positive values (Fig. 2A). In addition to changes in the corrosion potential, the flow in both the anodic and cathodic branches was decreased. The Tafel polarization of Robinia pseudoacacia L fruit extract at $1400 \mathrm{ppm}$ was shown showed that the inhibitory solution corrosion potential is $-216 \mathrm{mV}$, which compared to control solution, it has a shift of direction to positive values (Fig. 2(B)). The corrosion has also had a slight drop (Slight current drop) in the anodic and cathodic branches. The corrosion potential of the Robinia pseudoacacia $\mathrm{L}$ fruit extract was $-213 \mathrm{mV}$ at $1600 \mathrm{ppm}$ that it is showed displacement of $30 \mathrm{mV}$, compared to the corrosion solution (Fig. 2C). A slight drop (Slight current drop) is also observed in the anodic branch. The corrosion potential of the Robinia pseudoacacia L fruit extract was $-213 \mathrm{mV}$ at $1800 \mathrm{ppm}$ that it is showed displacement of $30 \mathrm{mV}$, compared to the corrosion solution (Fig. 2D). A slight drop (Slight current drop) is also observed in the anodic branch.

\section{The inhibitory efficiency of Robinia pseudoacacia $L$ fruit extract}

The analysis of variance were shown that the main effects (different concentrations of aqueous acacia extract and duration of treatment) as well as the interaction of the extract and duration were effective on corrosion inhibition $(\mathrm{P}<0.01)$ (Table 1$)$. Mean comparison showed that the highest rate of corrosion inhibition (93.5\%) was obtained at a concentration of $1800 \mathrm{ppm}$ and with increasing concentration of the extract, corrosion inhibition also increased, i.e., more bronze was prevented from burning (Fig. 3). Also, the highest corrosion inhibitory activity of Acacia extract (79.66) was in the second week and with increasing duration, this effect has decreased (Fig. 4).

Some traits like corrosion flow, corrosion potential, electrolyte resistance, flow density, cathodic and anodic slope coefficients, and corrosion rate of Robinia pseudoacacia L fruit investigated using Potentiostat device

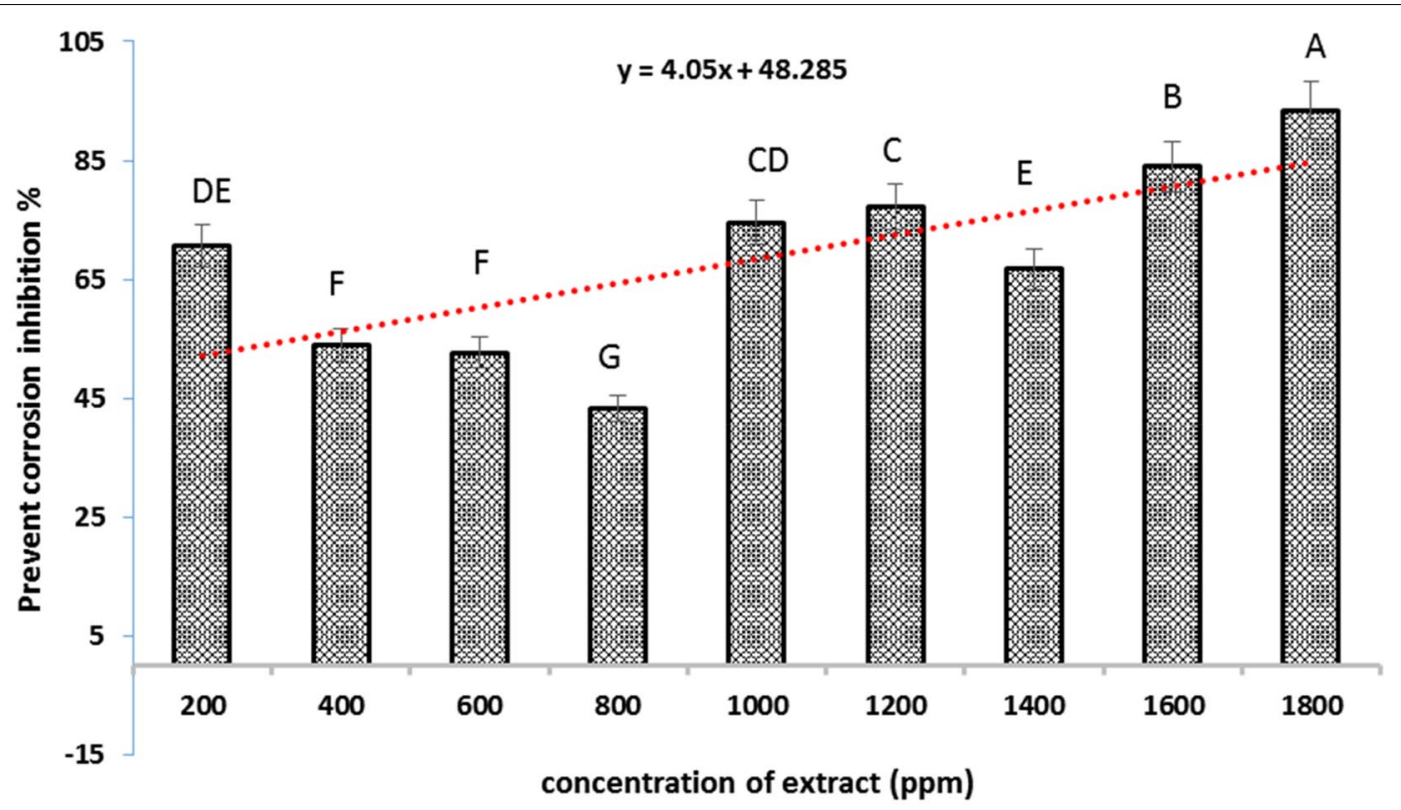

Fig. 3 Mean square of different concentrations of the aqueous extract of Acacia fruit on preventing corrosion inhibition of bronze (Similar letters indicate no significant differences in the treatments under study). $Y$ is equal to the regression equation 


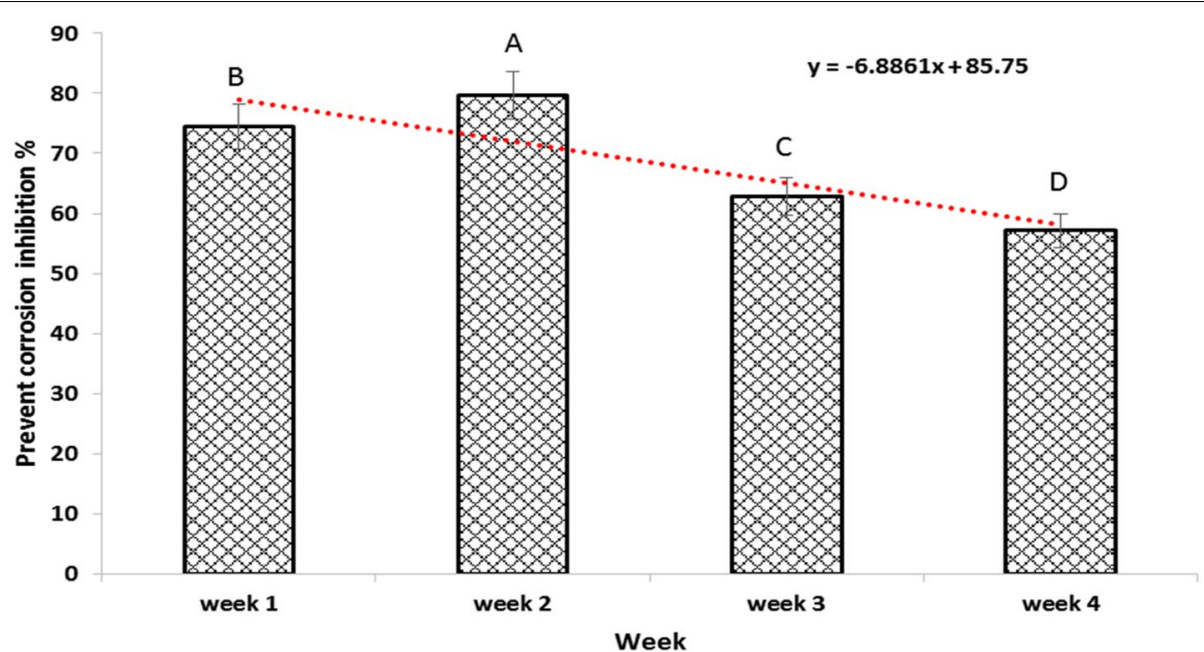

Fig. 4 The duration effect of Acacia fruit extract on bronze prevents corrosion inhibition (Similar letters indicate no significant differences in the treatments under study). $Y$ is equal to the regression equation

(Table 2). As the result, the relationship between potential, current intensity and corrosion diagram obtained based on the use of the anodic and cathodic hypertrophy, measuring the potential difference between this electrode and the reference electrode, as well as measuring the anodic and cathodic current intensity. The weight reduction rates of Robinia pseudoacacia L fruit extract were calculated using the data that they were derived from the Potentiostat device (Table 2).

The Weight-reduction rate method is the simplest in the study of corrosion inhibition due to the lack of need for a device. This experiment takes a long time, but because the results of this method are more realistic than the electrochemical method, it is still used.
The results of the analysis of variance showed that the effect of different concentrations of acacia aqueous extract on bronze weight reduction rate was significant $(\mathrm{P}<0.01)$. In the study of the weight reduction rate method, the results showed that the least weight reduction rate occurred at a concentration of $1800 \mathrm{ppm}$ of Acacia extract (Fig. 5), in general, the alloy weight loss was least with increasing the concentration of Acacia extract (Fig. 6). These results are the same as results that were obtained by device.

\section{Use of SEM to evaluate the performance of acacia fruit extract on the surface of coupons}

An aqueous extract of Acacia fruit can prevent corrosion of bronze using increasing the concentration but

Table 2 Calculation of corrosion flow, corrosion potential, electrolyte resistance, flow density, cathodic and anodic slope coefficients*, and corrosion rate of Robinia pseudoacacia $\mathrm{L}$ fruit with a Potentiostat device

\begin{tabular}{|c|c|c|c|c|c|c|c|}
\hline $\begin{array}{l}\text { Concentration Robinia } \\
\text { pseudoacacia L (W/V) }\end{array}$ & $-E_{\text {corr }}(m v)$ & $\mathbf{R}_{\mathrm{P}}$ (ohm) & $B_{a}(v / d e c)$ & $B_{c}(v / d e c)$ & I corrosion (A) & i corrosion $\left(A / \mathrm{cm}^{2}\right)$ & $\begin{array}{l}\text { Corrosion } \\
\text { rate (mpy) }\end{array}$ \\
\hline Blank & 243 & 800.5 & 0.060 & 0.066 & $2.716^{*} 10^{-5}$ & $6.497^{*} 10^{-5}$ & 28.381 \\
\hline 200 ppm & 211 & 1244 & 0.061 & 0.084 & $1.748^{*} 10^{-5}$ & $4.181^{*} 10^{-5}$ & 18.264 \\
\hline 400 ppm & 228 & 1315 & 0.072 & 0.079 & $1.653^{*} 10^{-5}$ & $3.955^{*} 10^{-5}$ & 17.276 \\
\hline 600 ppm & 214 & 1268 & 0.061 & 0.068 & $1.714^{*} 10^{-5}$ & $4.102^{*} 10^{-5}$ & 17.091 \\
\hline 800 ppm & 219 & 1508 & 0.082 & 0.090 & $1.442^{*} 10^{-5}$ & $30,449 * 10^{-5}$ & 15.066 \\
\hline 1000 ppm & 222 & 1765 & 0.059 & 0.072 & $1.232^{*} 10^{-5}$ & $2.947^{*} 10^{-5}$ & 12.873 \\
\hline 1200 ppm & 216 & 1573 & 0.067 & 0.095 & $1.382^{*} 10^{-5}$ & $3.306^{*} 10^{-5}$ & 14.441 \\
\hline 1400 ppm & 214 & 1734 & 0.077 & 0.108 & $1.254^{*} 10^{-5}$ & $2.99^{*} 10^{-5}$ & 13.100 \\
\hline 1600 ppm & 219 & 1218 & 0.076 & 0.104 & $1.785 * 10^{-5}$ & $4.27^{*} 10^{-5}$ & 18.652 \\
\hline 1800 ppm & 213 & 1029 & 0.121 & 0.117 & $2.113^{*} 10^{-5}$ & $5.054^{*} 10^{-5}$ & 22.077 \\
\hline
\end{tabular}

*Anodic and cathodic slopes were plotted on the anodic and cathodic branches and finally the device automatically calculated these slopes 


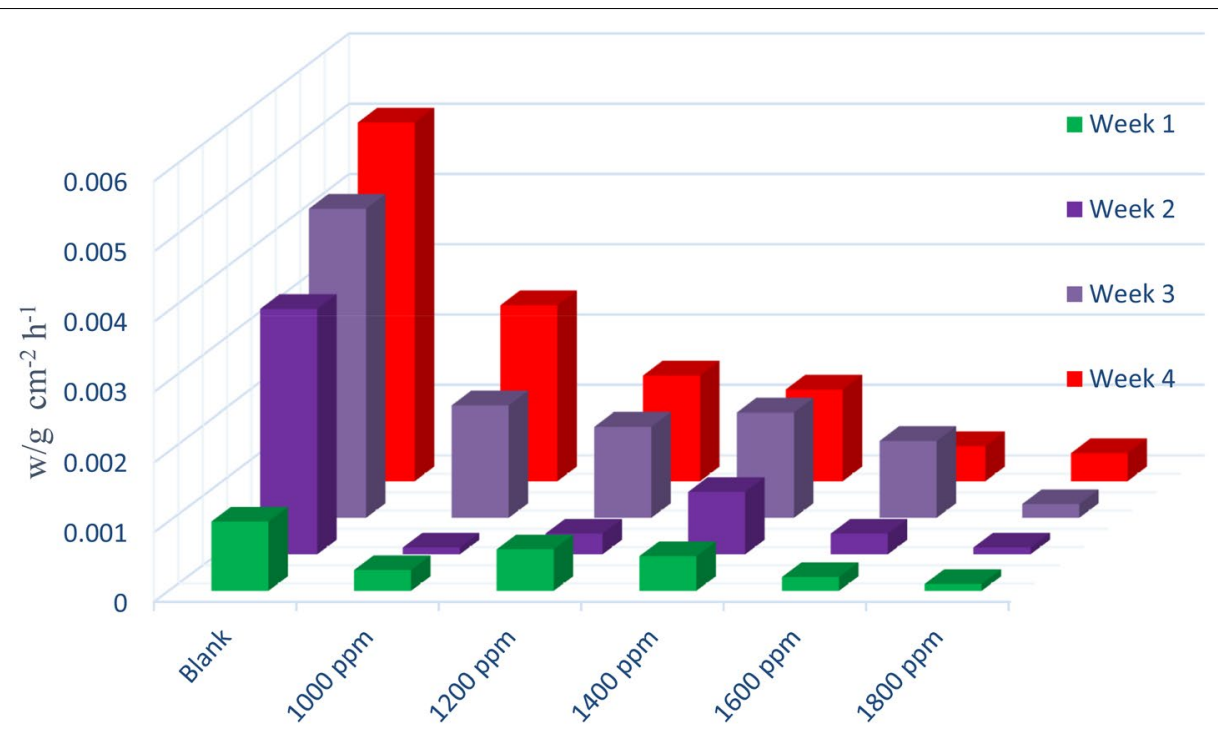

Acacia Concentrations

Fig. 5 The weight reduction rates based on 1800 ppm concentration of Robinia pseudoacacia L from 1 to 4 weeks floatation

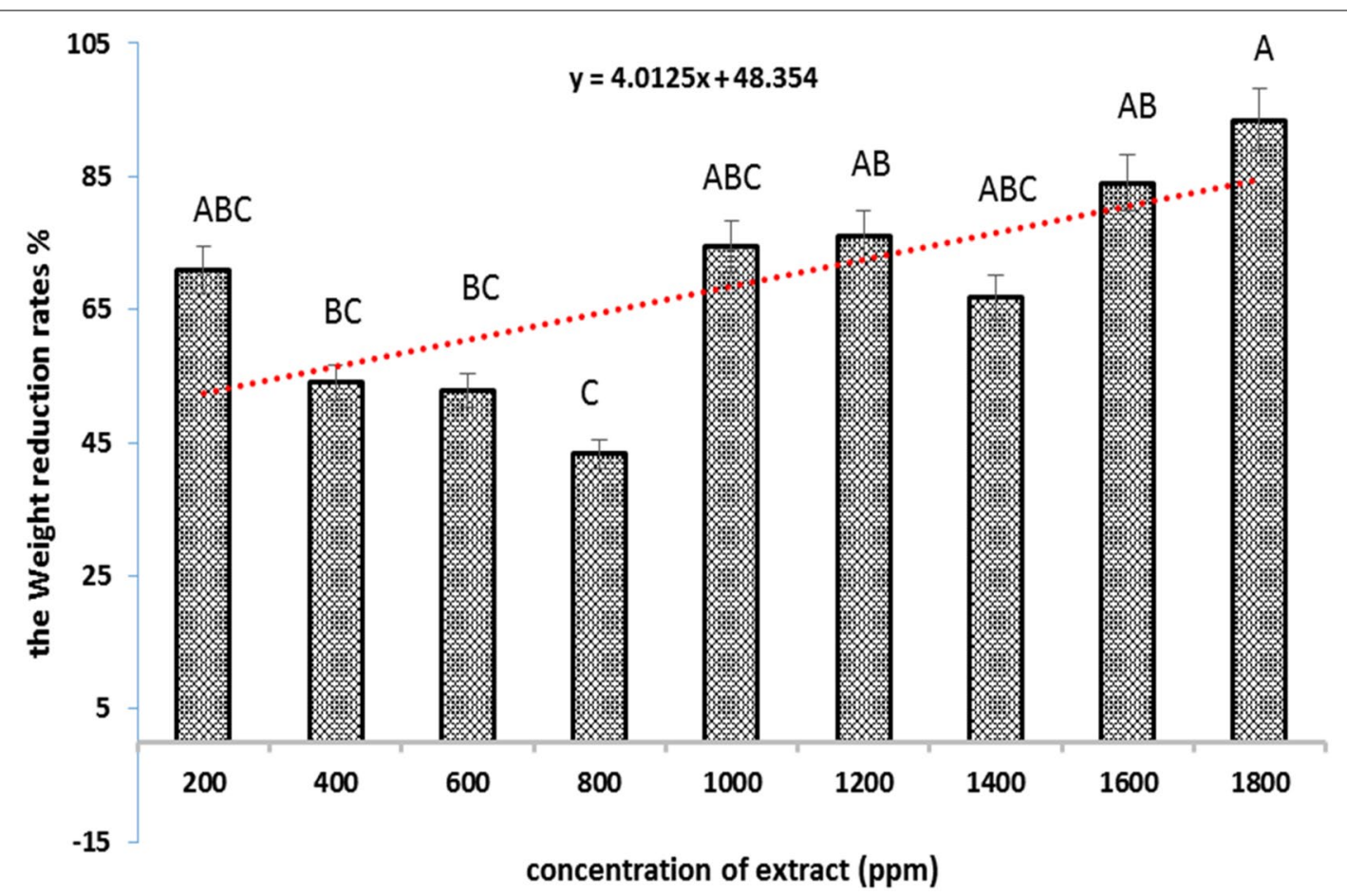

Fig. 6 Different concentrations effect of aqueous extract of acacia fruit on the weight reduction rate of bronze (Similar letters indicate no significant differences in the studied treatments)

to confirm the role of the extract, electron microscopy was used. After removing the coupons from the control (no extract) and aqueous extracts of Acacia fruit, the coupons were examined under a microscope to check the bronze level and corrosion. The examination of the surface of the control coupon revealed that it had green and localized corrosion products (Fig. 7). However, it was observed that the surface of the same coupons were 

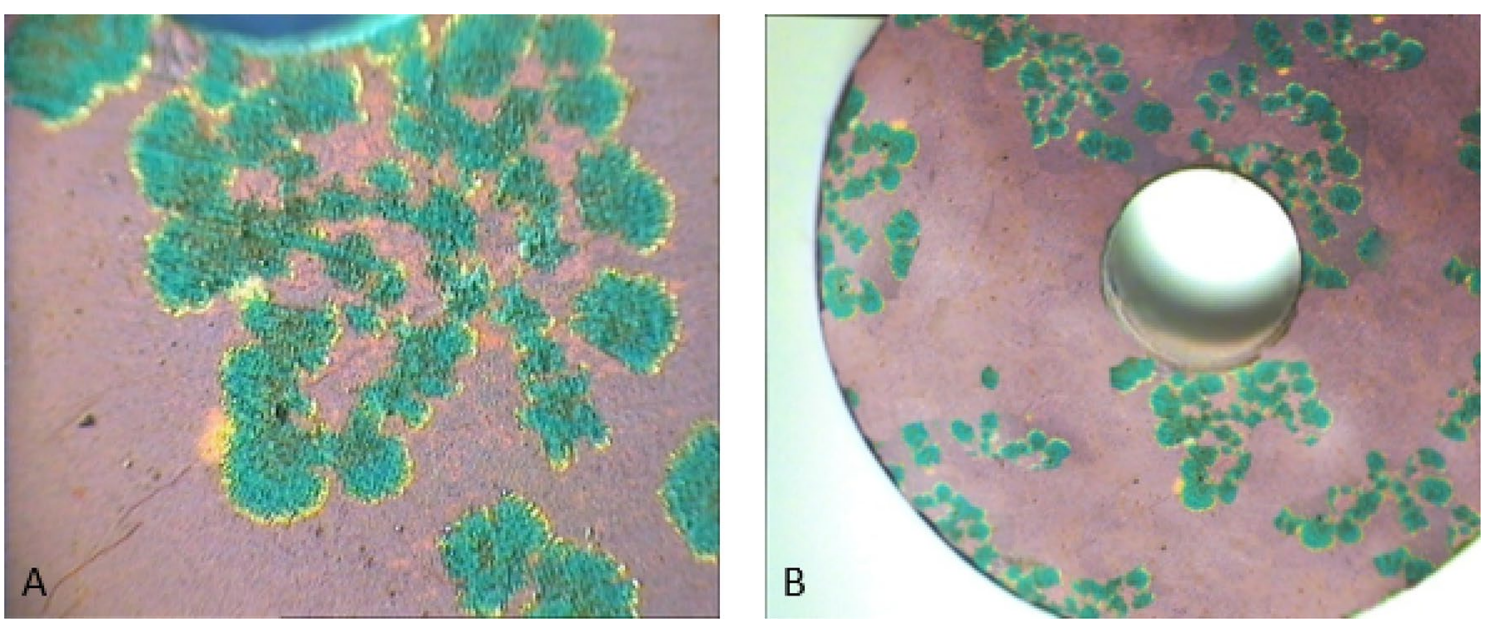

Fig. 7 A Coupons in a corrosive solution of sodium chloride 0.5 after 30 days of immersion. $\times 60$ magnification; $\mathbf{B}$ coupons in a corrosive solution of sodium chloride 0.5 after 30 days of immersion. $\times 40$ magnification

covered after being placed in corrosive solution and acacia extract (Fig. 8), and no trace of corrosion products were observed on the surface of the alloy (Fig. 9).

SEM was used to evaluate and accurately perform this inhibitor on the surface of these coupons. In the SEM images of the control coupon (Fig. 10), the corrosion products in the grain boundaries were identified and showed the high impact of the corrosive environment on this alloy. According to the morphology (needle and rhombus) of these corrosion products, can said that they are the type of atacamite and paratacamite that they have caused bronze disease in historical bronze works. These corrosion products are concentrated in the grain boundaries.

Although the aqueous extract of acacia fruit creates a uniform layer, which covers the surface of the alloy and prevents the formation of corrosion products on the surface of these coupons (Fig. 8) the SEM images showed that grain corrosion was induced in this alloy in the presence of acacia extract (Fig. 10). At higher concentrations of this extract, i.e. from 1000 to 1800 ppm, after immersion of the samples in the presence of acacia extract and $0.5 \mathrm{M}$ sodium chloride solution, the presence and growth of fungi have been observed, which can cause poor performance of acacia extract in the long run.
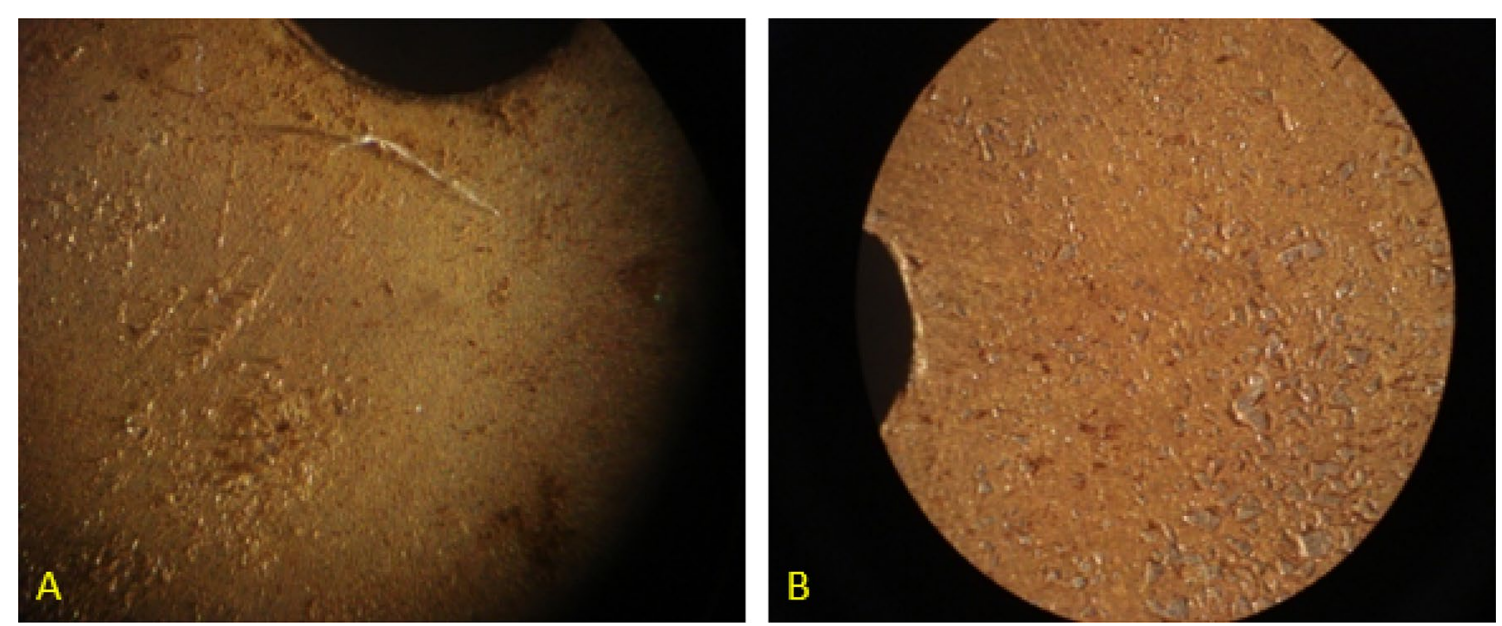

Fig. 8 A Coupon in the presence of Robinia pseudoacacia L inhibitor with a concentration of 1000 ppm after 30 days of immersion. $\times 60$ magnification; B coupon in the presence of Robinia pseudoacacia $L$ inhibitor with a concentration of 1800 ppm after 30 days of immersion. $\times 40$ magnification (B) 

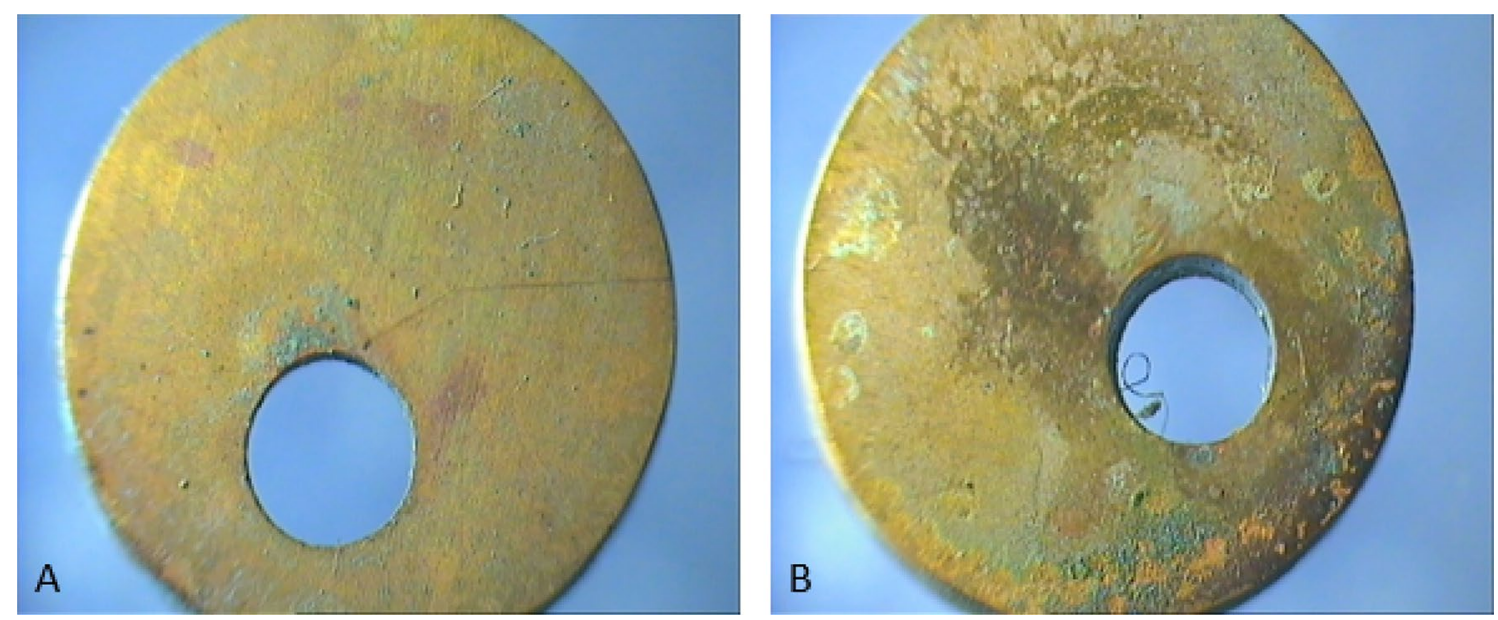

Fig. 9 A Coupon in the presence of Robinia pseudoacacia L inhibitor with a concentration of $1000 \mathrm{ppm}$ after 30 days of immersion. $\times 20$ magnification; $\mathbf{B}$ coupon in the presence of Robinia pseudoacacia $\mathrm{L}$ inhibitor with a concentration of $1800 \mathrm{ppm}$ after 30 days of immersion. $\times 20$ magnification
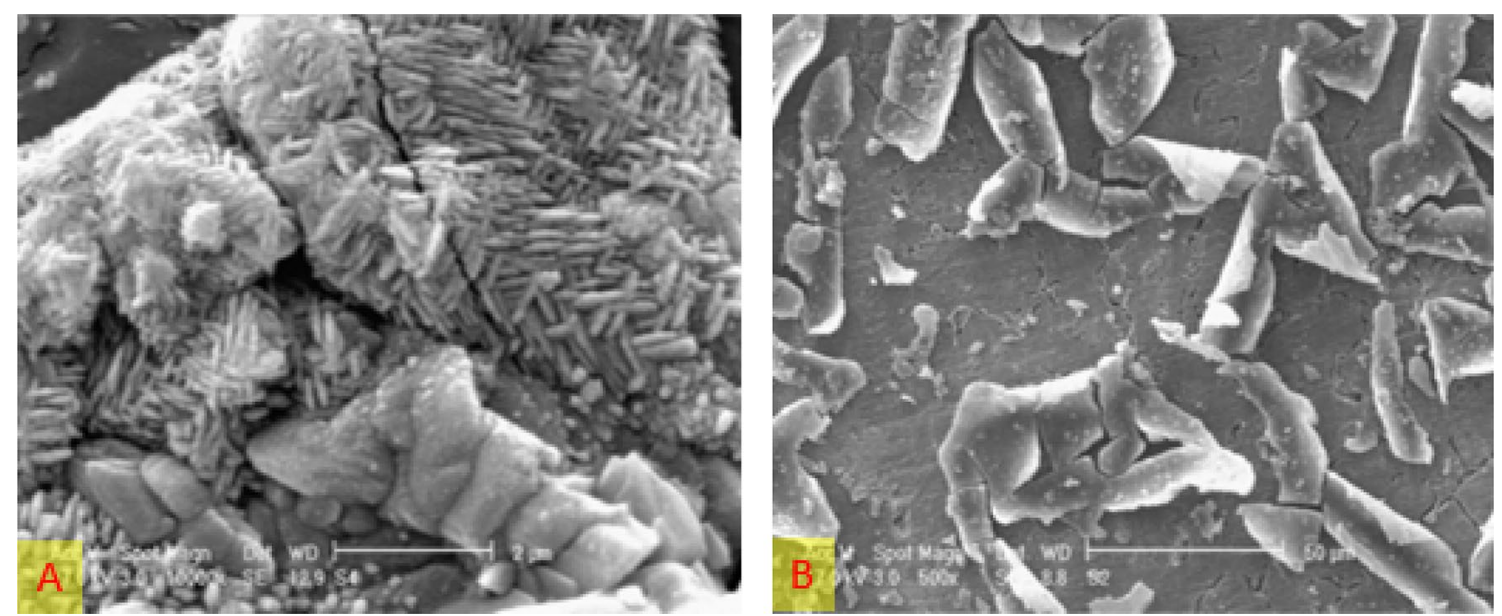

Fig. 10 A SEM analysis of control sample versus Sodium chloride $0.5 \mathrm{M}$ corrosive solution; B SEM analysis of coupon surface containing inhibitor at the presence of Sodium chloride $0.5 \mathrm{M}$ corrosive solution

EDX analysis of the control sample matrix showed that the amount of chlorine, which is the most important factor in the destruction of bronze disease, was 8.47 wt (Fig. 11). Based on the EDX results on the sample containing acacia extract, it can be concluded that the amount of chlorine detected was 3.20wt in the presence of corrosive sodium chloride solution after 4 weeks. These results indicate that the amount of chlorine in the presence of inhibitor was least (Fig. 12).

The green inhibitor of Acacia fruit aqueous extract can play an effective role in inhibiting corrosion of bronze, but the fungus has grown in the green inhibitor at higher concentrations and with increasing the duration of treatment. These fungi can reduce and even ineffective the role of Acacia fruit aqueous extract. Green inhibitors can play an effective role in preventing corrosion. However, to get better performance of these inhibitors, more tests need to be done to improve and optimize their performance.

\section{Discussion}

So far, different results have been reported regarding the use of plants extract on the prevention of corrosion. The extract of Salvia officinalis and its efficiency in corrosion inhibitory investigated in $0.5 \mathrm{M} \mathrm{Nacl}$. The results indicated that the extract of Salvia officinalis acted as a 


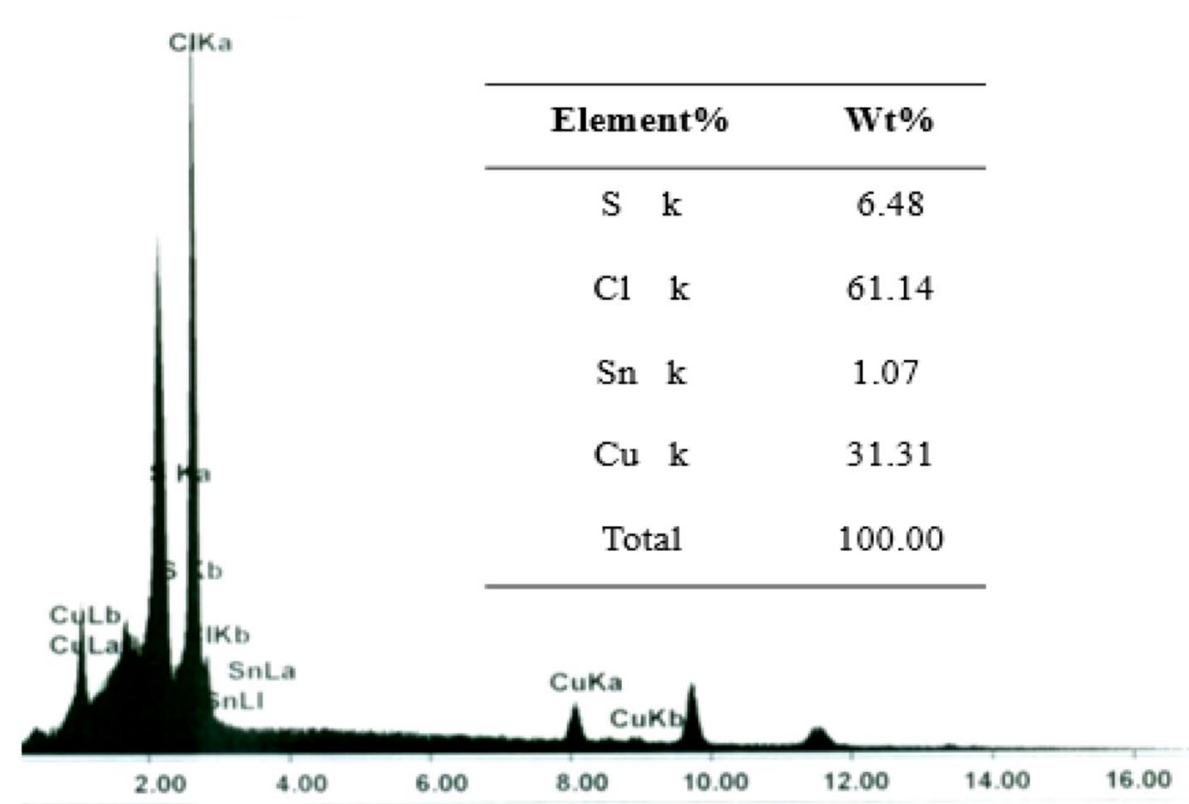

EDAX ZAF Quantification (Standardless)

Element Normalized

Fig. 11 EDX analysis of control sample versus Sodium chloride $0.5 \mathrm{M}$ corrosive solution

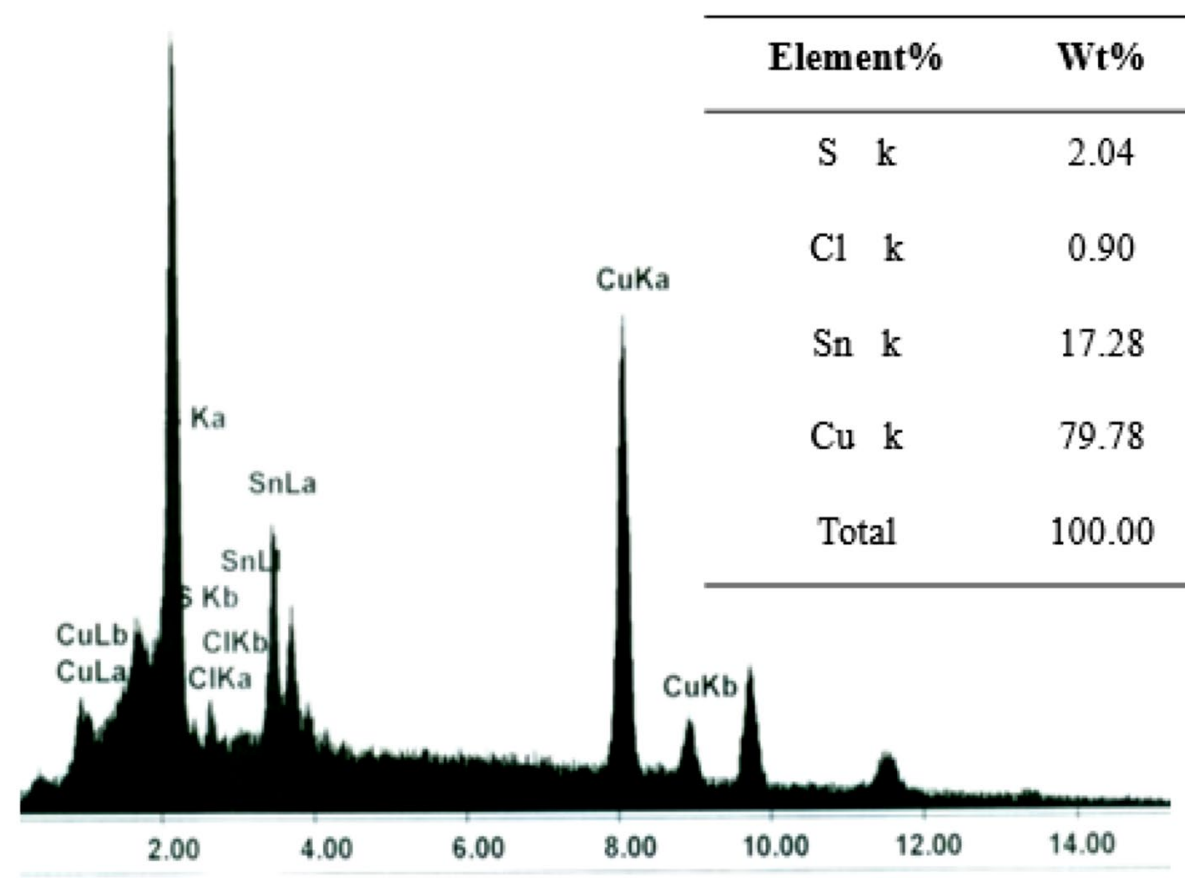

EDAX ZAF Quantification (Standardless)

Element Normalized

Fig. 12 EDX analysis of coupon surface containing inhibitor at the presence of Sodium chloride $0.5 \mathrm{M}$ corrosive solution 
cathodic inhibitor and the inhibitory efficiency increased with increasing sage extract concentration. The results of the weight loss test reported between 32 and 41\% [17].

In this study, the Potentiostat device method and the classic method of weight loss used to determine the efficiency of corrosion inhibitory. The results shown that this efficiency in the Potentiostat device method was 92\% but in the classical method was equal to $55 \%$ that more has been mentioned than research [17]. Because acacia contained flavonoids and phenolic compounds with a complex structure and high molecular weight, it was expected to prevent corrosion, but it did not.

The inhibitory effect of two natural honeys (oak and acacia) with a mixture of black horseradish juice on the corrosion of tin in aqueous media and sodium chloride solution by weight loss methods and polarization techniques has been studied. The results showed that the yield of acacia honey was lower than oak honey and by adding black horseradish juice to both honeys, their yield increased. The inhibition efficiency (IE) of all inhibitors examined obtained from both methods used a decrease in order: chestnut honey with black radish juice $>$ acacia honey with black radish juice $>$ chestnut honey $>$ acacia honey [48]. It has been found that acacia extract has less effect than black horseradish extract. In the present study, acacia extract had a positive effect at $1000 \mathrm{ppm}$, but with increasing acacia extract, the corrosion inhibitory effect decreased.

Natural honey has been studied as a corrosion inhibitor of carbon steel in high-salt environments. The inhibitory efficiency has been calculated through weight loss and static potential polarization technique. The results have introduced natural honey as a suitable inhibitor for corrosion of steel in high-salt environments. However, this beneficial effect has been limited to a certain level and after a while, due to the growth and development of fungi, its inhibitory efficiency has been reduced [20]. It is indicated that, after some time, the inhibition efficiency decreased due to the growth of fungi in the medium. Because they said that the effect of fungi on the inhibition efficiency of natural honey is markedly decreased in high saline water and also the high concentration of $\mathrm{NaCl}$ may retard the growth of fungi [49]. In the present study, acacia extract had a fungal growth of $1800 \mathrm{ppm}$, which over time reduced the inhibitory effect.

Inhibition of organic compounds such as honey and rosemary (Salvia rosmarinus L.) on four metals, aluminum, copper, iron and zinc in sodium chloride and sodium sulfate solution has been investigated. The results showed that the inhibitors had no effect on aluminum in sodium chloride and sodium sulfate solutions. The reason why honey is not inhibited is that honey plays a small cathodic inhibitory role in aluminum when placed in polarized sodium chloride solution [2]. Perhaps the reason for not increasing the inhibition of Acacia extract by increasing the concentration of the extract to $1800 \mathrm{ppm}$ and the inhibition oscillation between cathode and anodic is also because the role of cathodic and anodic inhibition after oscillation in polarized sodium chloride solution has decreased. However, it can have another reason, such as less absorption power on the bronze (Cu-10Sn).

In this research, on the bronze surface, there were active cathodic sites in contact with corrosive species, which results in a vigorous dissolution of bronze. Bronze surface can be protected against the charge and mass transfer which causes corrosion by adsorption of the green organic components. This result is similar to the previous research [50].

The Corrosion Inhibition by Beet Root (BR) Extract was conducted and the results shown that the BR extract with $50 \mathrm{ppm} \mathrm{Zn}^{2+}$ had about $98 \%$ inhibition efficiency to carbon steel immersed in well water (a mixed-type effect existed between $\mathrm{BR}$ extract and $\mathrm{Zn}^{2+}$ ) [51]. The results herein indicated that the type of inhibitor was mixedtype inhibitor.

The acacia leaves extract was used as an eco-friendly inhibitor on mild steel in acidic media and it easily extractable, extremely inexpensive, environmentally safe and effective in slowing mild steel corrosion which is not formerly used in corrosion studies. Hence, the acacia leaves extract can be used as a potential corrosion inhibitor in the acidic environment for mild steel [50]. In the present study, acacia extract had a positive effect but the corrosion inhibitory effect decreased with increasing acacia extract.

\section{Conclusion}

Given the investigations on Robinia pseudoacacia L fruit using potentiostat device, it was revealed that Robinia pseudoacacia L fruit had inhibitory efficiency at $1800 \mathrm{ppm}$ with a corrosion rate of $12.78 \%$ is $55 \%$ for bronze alloy with percentage of $(\mathrm{Cu}-10 \mathrm{Sn})$ and has a mixed inhibitory effect. In the classic weight reduction rate, (in which the results are more real than those in electrochemical methods), the inhibitory efficiency of Robinia pseudoacacia L fruit was determined to be $92 \%$. SEM images derived from the surface of coupons at the presence of Robinia pseudoacacia L and a corrosive solution of sodium chloride $0.5 \mathrm{M}$ shown a kind of segregation on the surface of coupons in the presence of a corrosive solution. Based on the experiments performed, it is necessary to add other natural compounds to this inhibitor for better efficiency so that appropriate and optimal conditions for this type of inhibitor can be defined. 
One of the points that should be considered during the restoration process is not to change the structure and appearance of the historical monument. Since corrosion in a metal monument, especially copper and bronze, has a special place and importance from a historical, structural and sometimes aesthetic point of view. Based on our result, it seems necessary to pay more attention to the rate of color changes after the application of new materials.

\begin{abstract}
Abbreviations
AMT: 5-Amino-2-mercapto-1,3,4-thiadiazole; ANOVA: Analysis of variance; ASTM: American Society for Testing and Materials; BTA: Benzotriazole; EDX: Energy Dispersive X-rays; LSV: Liner sweep voltammetry; mV: Millivolts; PPM: Part Per Million; RCD: Randomized complete design; SEM-EDX: Scanning Electron Microscope-Energy Dispersive X-rays.
\end{abstract}

\section{Acknowledgements}

We thereby appreciate Dr. Vatan Khah, Dr. Emami and Dr. Abed Esfahani, who helped us in this research.

\section{Authors' contributions}

VP and BFN designed the research and wrote the paper. Both authors read and approved the final manuscript.

\section{Funding}

Not applicable.

\section{Availability of data and materials}

All the data is embedded in the manuscript.

\section{Declarations}

Ethics approval and consent to participate

No human or animals were used in the present research.

\section{Consent for publications}

All authors read and approved the final manuscript for publication.

\section{Competing interests}

All authors declare no conflict of interest exists.

\section{Author details}

'Department of Historical Works Restoration, Faculty of Art and Architecture, University of Zabol, Zabol, Iran. ${ }^{2}$ Research Department of Agronomy and Plant Breeding, Agricultural Research Institute, University of Zabol, Zabol, Iran.

Received: 16 April 2021 Accepted: 4 June 2021

Published online: 18 June 2021

\section{References}

1. Verma C, Ebenso EE, Quraishi M. Ionic liquids as green and sustainable corrosion inhibitors for metals and alloys: an overview. J Mol Liq. 2017;233:403-14. https://doi.org/10.1016/j.molliq.2017.02.111.

2. Yee Y. Green inhibitors for corrosion control: a Study on the inhibitive effects of extracts of honey and rosmarinus officinalis L.(Rosemary): MS thesis, University of Manchester, Institute of Science and Technology; 2004

3. Saeed MT, Saleem M, Niyazi AH, Al-Shamrani FA, Jazzar NA, Ali M. Carrot (Daucus carota L.) peels extract as an herbal corrosion inhibitor for mild steel in 1M HCl solution. Modern Appl Sci. 2020;14(2):97-112.

4. Miralrio A, Espinoza VA. Plant extracts as green corrosion inhibitors for different metal surfaces and corrosive media: a review. Processes. 2020:8(8):942. https://doi.org/10.3390/pr8080942.
5. Al-Moubaraki AH, Al-Howiti AA, Al-Dailami MM, Al-Ghamdi EA. Role of aqueous extract of celery (Apium graveolens L.) seeds against the corrosion of aluminium/sodium hydroxide systems. J Environ Chem Eng. 2017;5(5):4194-205. https://doi.org/10.1016/j.jece.2017.08.015.

6. Olajire AA. Corrosion inhibition of offshore oil and gas production facilities using organic compound inhibitors-a review. J Mol Liq. 2017;248:775-808. https://doi.org/10.1016/j.molliq.2017.10.097.

7. Barreto LS, Tokumoto MS, Guedes IC, Melo HG, Amado FDR, Capelossi VR. Evaluation of the anticorrosion performance of peel garlic extract as corrosion inhibitor for ASTM 1020 carbon steel in acidic solution. Matéria. 2017. https://doi.org/10.1590/s1517-707620170003.0186.

8. Groysman A. Corrosion for everybody. Springer; 2009. https://doi.org/10. 1007/978-90-481-3477-9

9. Ogawa A, Takakura K, Hirai N, Kanematsu H, Kuroda D, Kougo T, et al. Biofilm formation plays a crucial rule in the initial step of carbon steel corrosion in air and water environments. Materials. 2020;13(4):923. https:// doi.org/10.3390/ma13040923.

10. Rani B, Basu BBJ. Green inhibitors for corrosion protection of metals and alloys: an overview. International Journal of corrosion. 2012. https://doi. org/10.1155/2012/380217.

11. Palanisamy G. Corrosion inhibitors. Corrosion inhibitors: Ambrish Singh, IntechOpen; 2019. p. 1-24. https://doi.org/10.5772/intechopen.80542

12. Faltermeier RB. A corrosion inhibitor test for copper-based artifacts. Studies in conservation. 2013;44(2):121-8. https://doi.org/10.1179/sic.1999. 44.2.121.

13. Artesani A, Di Turo F, Zucchelli M, Traviglia A. Recent advances in protective coatings for cultural heritage-an overview. Coatings. 2020;10(3):217. https://doi.org/10.3390/coatings10030217.

14. Faltermeier RB, Archaeology UoLIo. AMT: A New Corrosion Inhibitor? : University College; 1992. p. 44 Pages.

15. Kumara SA, Sankar A, Kumarb SR, Vijayanc M. Asparagus racemosus root extract as corrosion inhibitor for mild steel in acid medium. Int J Comput Eng Sci. 2013;3(1):40-5.

16. Pourzarghan V, Sarhaddi-Dadian H, Bakhshandefard H. Feasibility study of natural honey use as corrosion inhibitor in protecting the bronze artifacts. Mediter Archaeol Archaeom. 2017;17(3):301-9. https://doi.org/ 10.5281/zenodo.1048935.

17. Vatankhah GR, Bakhshandehfard HR, Golozar MA, Sabzalian MR. Salvia officinalis extract as a natural corrosion inhibitor for copper alloy artifacts treatment. Sci J Maremat \& Me'mari-e Iran. 2011;1(1):41-54.

18. Vatankhah GR, Bakhshandehfard HR, Golozar MA, Sabzalian MR. Green tea extract (Camellia sinensis): a non-toxic plant inhibitor for controlling corrosion in historical copper artifacts. Sci J Maremat \& Me'mari-e Iran (quarterly). 2013;1(4):85-96.

19. Kliškić M, Radošević J, Gudić S, Katalinić V. Aqueous extract of Rosmarinus officinalis L. as inhibitor of Al-Mg alloy corrosion in chloride solution. J Appl Electrochem. 2000;30(7):823-30. https://doi.org/10.1023/A:10040 41530105.

20. El-Etre A. Natural honey as corrosion inhibitor for metals and alloys. I. Copper in neutral aqueous solution. Corrosion Sci. 1998;40(11):1845-50. https://doi.org/10.1016/S0010-938X(98)00082-1.

21. El-Etre A. Inhibition of aluminum corrosion using Opuntia extract. Corros Sci. 2003;45(11):2485-95. https://doi.org/10.1016/S0010-938X(03) 00066-0.

22. Abiola OK, Oforka NC, Ebenso EE, Nwinuka NM. Eco-friendly corrosion inhibitors: the inhibitive action of Delonix regia extract for the corrosion of aluminium in acidic media. Anti-Corros Methods Mater. 2007;54(4):21924. https://doi.org/10.1108/00035590710762357.

23. Rotaru I, Varvara S, Gaina L, Muresan LM. Antibacterial drugs as corrosion inhibitors for bronze surfaces in acidic solutions. Appl Surf Sci. 2014;321:188-96. https://doi.org/10.1016/j.apsusc.2014.09.201.

24. Al-Nami S, Fouda AE-AS. Corrosion Inhibition Effect and Adsorption Activities of methanolic myrrh extract for Cu in $2 \mathrm{M} \mathrm{HNO3.} \mathrm{Int} \mathrm{J} \mathrm{Electro-}$ chem Sci. 2020;15:1187-205. https://doi.org/10.20964/2020.02.23.

25. Liu Z, Hu B, Bell TL, Flemetakis E, Rennenberg H. Significance of mycorrhizal associations for the performance of N2-fixing Black Locust (Robinia pseudoacacia L.). Soil Biol Biochem. 2020;145:107776. https://doi.org/10. 1016/j.soilbio.2020.107776.

26. Scott DA. Ancient metals: microstructure and metallurgy: Lulu. com; 2011. 
27. Karamalla K, Siddig N, Osman M. Analytical data for Acacia senegal var senegal gum samples collected between 1993 and 1995 from Sudan. Food hydrocolloids. 1998;12(4):373-8. https://doi.org/10.1016/S0268005X(98)00005-8.

28. Mohamed AM, Ariffin MAM, Smaoui H, Osman MH. Performance evaluation of concrete with Arabic gum biopolymer. Mater Today. 2020. https:// doi.org/10.1016/j.matpr.2020.04.576.

29. Raja PB, Sethuraman MG. Natural products as corrosion inhibitor for metals in corrosive media-a review. Mater Lett. 2008;62(1):113-6. https:// doi.org/10.1016/j.matlet.2007.04.079.

30. Buchweishaija J, Mhinzi G. Natural products as a source of environmentally friendly corrosion inhibitors: the case of gum exudate from Acacia seyal var seyal. Portugaliae Electrochimica Acta. 2008;26(3):257-65.

31. Nasab SG, Yazd MJ, Semnani A, Kahkesh H, Rabiee N, Rabiee M, et al. Natural corrosion inhibitors. Synth Lect Mech Eng. 2019;14(1):1-96. https://doi.org/10.2200/S00910ED1V01Y201903MEC018.

32. Mohyaldinn ME, Lin W, Gawi O, Ismail MC, Ahmed QA, Ayoub MA, et al., editors. Experimental Investigation of a New Derived Oleochemical Corrosion Inhibitor. Key Engineering Materials; 2019: Trans Tech Publ. https:// doi.org/10.4028/www.scientific.net/KEM.796.112

33. Fazeli-Nasab B, Sirousmehr A, Mirzaei N, Solimani M. Evaluation of total phenolic, flavenoeid content and antioxidant activity of Leaf and Fruit in 14 different genotypes of Ziziphus mauritiana L. in south of Iran. EcoPhytochem J Med Plants. 2017:4(4):1-14.

34. Goss-Sampson M. Statistical analysis in JASP: A guide for students: JASP; 2019. https://doi.org/10.6084/m9.figshare.9980744

35. Allen JB, Larry RF. Electrochemical methods fundamentals and applications: John Wiley \& Sons; 2001. ISBN: 0-471-04372-9

36. Li Y, Xu N, Guo X, Zhang G. Inhibition effect of imidazoline inhibitor on the crevice corrosion of $\mathrm{N} 80$ carbon steel in the $\mathrm{CO} 2$-saturated $\mathrm{NaCl}$ solution containing acetic acid. Corros Sci. 2017;126:127-41. https://doi.org/ 10.1016/j.corsci.2017.06.021.

37. Wang H-L, Liu R-B, Xin J. Inhibiting effects of some mercapto-triazole derivatives on the corrosion of mild steel in $1.0 \mathrm{M} \mathrm{HCl}$ medium. Corros Sci. 2004:46(10):2455-66. https://doi.org/10.1016/j.corsci.2004.01.023.

38. Rybalka K, Beketaeva L, Davydov A. Determination of corrosion current density by the rate of cathodic depolarizer consumption. Russ J Electrochem. 2016;52(3):268-72. https://doi.org/10.1134/S1023193516030095.

39. Standard A. Standard practice for calculation of corrosion rates and related information from electrochemical measurements. Annu Book ASTM Stand ASTM Int West Conshohocken PA. 2006;3:G102-89. https:// doi.org/10.1520/G0102-89R15E01.

40. Dean S. Calculation of alloy equivalent weight. Mater Perform. 1987;26(12):51-2
41. Tan X, Zhi Q, Yang R, Wang F, Yang J, Liu Z. Effects of milling on the corrosion behavior of Al2 NbTi3V2Zr high-entropy alloy system in 10\% nitric acid solution. Mater Corros. 2017;68(10):1080-9. https://doi.org/10.1002/ maco.201709472.

42. Tang L, Li X, Li L, Mu G, Liu G. The effect of 1-(2-pyridylazo)-2-naphthol on the corrosion of cold rolled steel in acid media: Part 2: Inhibitive action in 0.5 M sulfuric acid. Mater Chem Phys. 2006;97(2-3):301-7. https://doi.org/ 10.1016/j.matchemphys.2005.08.014.

43. Pourfarzad H, Shabani-Nooshabadi M, Ganjali MR, Olia MH. Inhibition of acid corrosion of glass ampoule in $\mathrm{Pb} / \mathrm{HBF} 4 / \mathrm{PbO} 2$ reserve batteries using nanobis [3-(trimethoxysilyl) propyl] amine. J Mol Liq. 2020;302: 112578. https://doi.org/10.1016/j.molliq.2020.112578.

44. de Rooij M. Electrochemical methods: fundamentals and applications. Anti-Corros Methods Mater. 2003. https://doi.org/10.1108/acmm.2003. 12850 eae.001.

45. Bard AJ, Faulkner LR. Fundamentals and applications. Electrochem Methods. 2001;2(482):580-632.

46. Pourzarghan V, Vatankhah G, Bakhshandeh-Fard HR. Investigation and feasibility of using honey as a corrosion inhibitor in the protection of historical bronze objects. Isfahan: Master Thesis on Restoration of Historical Works of Art University of Isfahan; 2010.

47. Goyal M, Vashist H, Kumar S, Bahadur I, Benhiba F, Zarrouk A. Acid corrosion inhibition of ferrous and non-ferrous metal by nature friendly ethoxycarbonylmethyltriphenylphosphonium bromide (ECMTPB): experimental and MD simulation evaluation. J Mol Liq. 2020;315: 113705. https://doi.org/10.1016/j.molliq.2020.113705.

48. Radojčić I, Berković K, Kovač S, Vorkapić-Furač J. Natural honey and black radish juice as tin corrosion inhibitors. Corros Sci. 2008;50(5):1498-504. https://doi.org/10.1016/j.corsci.2008.01.013.

49. El-Etre A, Abdallah M. Natural honey as corrosion inhibitor for metals and alloys. II. C-steel in high saline water. Corros Sci. 2000;42(4):731-8. https:// doi.org/10.1016/S0010-938X(99)00106-7.

50. Yüce AO. Corrosion inhibition behavior of Robinia pseudoacacia leaves extract as a eco-friendly inhibitor on mild steel in acidic media. Met Mater Int. 2020;26(4):456-66. https://doi.org/10.1007/s12540-019-00509-7.

51. Selvi JA, Rajendran S, Sri VG, Amalraj AJ, Narayanasamy B. Corrosion inhibition by beet root extract. Port Electrochim Acta. 2009;27(1):1-11. https://doi.org/10.4152/pea.200901001.

\section{Publisher's Note}

Springer Nature remains neutral with regard to jurisdictional claims in published maps and institutional affiliations.

\section{Submit your manuscript to a SpringerOpen ${ }^{\circ}$ journal and benefit from:}

- Convenient online submission

- Rigorous peer review

- Open access: articles freely available online

- High visibility within the field

Retaining the copyright to your article

Submit your next manuscript at springeropen.com 